\title{
Study on Multi-Level Accounting Personnel Training Mode based on Coordinated Development of Vocational Education and Subject Education
}

\author{
Dongdong $\mathrm{Li}^{1, \mathrm{a}}$ \\ ${ }^{1}$ Accounting College, Wuhan Textile University, Wuhan, Hubei, 430077 \\ ${ }^{a}$ email
}

Keywords: Personnel Training, Subject Education, Accounting, Vocational Education

\begin{abstract}
Under the new normal economy, the social demand for accounting professionals have shown a significant structural change in demand due to graduates of vocational colleges and the community to supply accounting personnel asymmetry. On the one hand is rising social demand for high-quality, high-quality accounting personnel, on the other hand is due to the professional quality of graduates do not reach the business requirements resulting in lower employment. In this paper, both vocational education and sciences education vocational training model aimed at solving the tertiary institutions Professional Accounting student employment, raising the employment rate on this basis, to make a long-term big data era graduates accounting career planning.
\end{abstract}

\section{Introduction}

With the advent of the information age, our country is now in the stage of industrial restructuring, greater downward pressure on the economy and businesses demand for accounting professionals than ever are greater changes. Talent supply and demand market is showing a serious dilemma, on the one hand a large number of fresh accounting graduates can not find suitable jobs, on the other hand is one of many employers because they can not be satisfied accounting personnel. In order to determine the relationship between higher education in accounting and personnel needs of the community, I have done a lot of market research, we used to visit and survey information and personnel recruitment websites etc. Demand for Higher School of Accounting Talents Wuhan Textile University conducted three consecutive years of investigation and analysis. The results showed that the main destination of Higher Accounting Majors employment SMEs, especially small and micro enterprises, these students accounted for a total of $93 \%$ of the student employment. Through the survey also found that a large number of small and micro enterprises made it clear that the requirements of the demand side of the accounting staff and large state-owned enterprises and listed companies have very different. It requires accounting personnel can have a diploma. It depends on small and micro enterprises small scale, small business, the accounting treatment is relatively simple. We found that small and micro enterprises to provide accounting post group mainly accounting, financial management, internal audit group of three jobs, jobs graduates are mainly distributed in the cashier and cashier, accounting, cost accounting, warehouse, marketing, and other five post. SMEs because of the relatively low wages, higher education for undergraduate and postgraduate accounting personnel can not keep, so small and medium enterprises, especially small enterprises are the main destination of Higher Accounting graduates. SME finance manager and chief financial officer job requirements Decision accountant talents, academic requirements undergraduate, graduate, and the ability to adapt to the grass-roots cashier and accounting positions and have no practical ability to adapt to other positions and generalist.

\section{Accounting Problems in Local Personnel Training of Vocational College}

Accounting specialist teaching model mostly referring undergraduate accounting professional teaching mode, since there is a big difference in the quality of teachers and students, although teaching modes, trained accounting personnel but the good and the bad. This is similar to a 
technical strength of strong business and technical strength of a weak business while producing the same product, technical strength and weak corporate product must not be robust enterprise products to compete with technical strength and technical strength for the weak enterprises, adopt this marketing strategy is tantamount to self-defeating. Students present theoretical accounting personnel training mode most colleges do not have their own characteristics as well as location, so that the lack of culture, practice is not fine, difficult to adapt to market demand for accounting graduates \# colleges and more employment in SMEs, although this enterprises accounting business is relatively simple, but due to the small accounting staffing "division of labor is not clear, an accountant to bear a lot of work, not only to be accounting, we need to understand the bank" business taxation, or even responsible for financial budgeting "performance assessment and other management accounting training model \# but most colleges still follow the traditional model train accounting personnel based mainly accounting for taxation and banking is not fine \# lack of students in practical work necessary professional skills and culture experience, leading practitioners after students feel and learn what they have learned there is a certain discrepancy.

The main problem of Accounting Curriculum exist in the following three aspects: first, the curriculum was repeated, outstanding performance in cost accounting, financial management and management accounting in part repeat, advanced financial accounting and business combinations duplicate parts, solid accounting software Practical training such as financial business integration with ERP training content cross. Analysis of the main reasons is fragmented among professional teachers, as well as the lack of prior, during and after the communication between teachers and between the Department of Internal Department, or there is not the same course syllabus unified phenomenon. Second, the emphasis on universal lesson settings and basic theory courses, and professional training courses set up unreasonable, first a small range of training courses, followed by hours of training courses is much lower than undergraduate training class, this type of training of professional personnel accounting serious departure. Some lack the necessary teaching contents lead to a general lack of student analysis and decision-making ability. Third, the curriculum is not comprehensive, accounting system design, analysis of financial statements and business combinations, office software application courses opened with some problems. Not rich set of elective courses, the creation of inadequate human resources accounting, environmental accounting, strategic management accounting, tax accounting courses, students can not meet the interest and demand for long-term career planning.

College accounting education of professional teachers less, "many students often take classes when triple, teaching large classes taught combo main teaching method is to use PPT teaching, using the traditional teacher, students listen method, case rarely used in teaching vocational students in the classroom, which led classroom interaction is not strong, can not fully mobilize the enthusiasm and initiative of students, teachers teaching in order to save, between, more classroom lectures, discussions fewer students divergent thinking too not improve.

After class students in-depth business practice fewer opportunities, although some students went on vacation internship, but only a handful of teachers along with the accounting profession, not a direct result of the students' practical guidance on, the students do not know how practical problems encountered deal with.

The lack of a qualified majority of two qualified teachers Vocational Colleges. The "Double" teachers construction are precisely the key to improving the quality of vocational education. Construction of the accounting profession as a whole needs a high-quality, skilled teachers. On the current situation in China Vocational College accounting point of view, both a solid foundation of accounting theory and familiar "Double Teachers" practical resource scarcity. There are a lot of the Higher Colleges of "Double Teachers" understood as "Double Certificates" teachers, in fact, this is very unscientific. "Double" to emphasize that the accounting theory and practice of mastery, and "Double Certificates" can only illustrate the theoretical knowledge, but does not represent the actual operating capacity is very strong. Most accounting teacher in higher vocational colleges are graduating from colleges and universities directly engaged in teaching, enrich the theory of knowledge, but because there is no actual experience in accounting, likely to cause disjointed 
teaching and practice, practice is difficult to guarantee the quality of teaching. Many colleges accounting profession is divided from management "economics" out of mathematics and other professional accounting from a basic course derive more professional courses, with the increase of professional courses, teaching tasks increased, the quality of teaching can not be guaranteed in the short term.

Assistant Accountant direction "Accounting + OFFICE / WPS + ERP" as the core module, through the introduction of accounting qualification exam. Content, the "Vocational Education + job skills education" mode. The vocational training program is mainly for students their qualification at this level. In the background of the information society and big data, it is necessary to act as accounting positions, bear some secretarial role. Financial work with a computer merging is the trend, so, as a financial worker in the information age, should be more to study and explore Office feature that lets computer services for financial operations. As with the further development of information technology, computerized accounting system is also fast to the network, intelligent forward, between enterprises and banks a lot of business transactions can now be able to provide electronic statements made by the banks, and the use of financial software unit accounting books also can be exported in Excel format. This provides the preconditions for electronic reconciliation; accounting personnel according to their work experience and job requirements, use the power of Excel to simplify procedures and improve efficiency. Well-known work of the cashier rather cumbersome, require daily handle a large number of documents, these documents are currently mostly filled out by hand, such as checks and Jinzhang Dan, we know very demanding artificial write a check, do not say human consumption, but also very prone to error ,Time-consuming. In this case, the cashier can use Excel independent design some personalized documents chromatography printing format, which undoubtedly can greatly improve cashier efficiency.

The basic course is set in line with most accounting professional institutions set up, this is no longer tired. Given the training program for the "Accounting + OFFICE / WPS + ERP" this level of grassroots accounting personnel, so it is a result of the additional Office or wps office software training courses, and to ensure there is enough computer time, evaluation methods should focus on on test.

Basic Course settings should take into account the need for the most basic accounting features of the accounting work of college graduates, this level accounting personnel must have basic theoretical knowledge in order to understand the significance of accounting work, improve work efficiency. Therefore, the basic course should be taught: Principles of Economics, principles of management, principles of statistics, financial regulations and accounting professional ethics, economic law, tax law, accounting principles, accounting, accounting qualification certificate examination training.

Compulsory settings should focus on vocational accounting students after graduation and long-term career planning and personal development and therefore need to increase the junior professional accounting qualification examination content requirements under the premise of the basic course has been set up, and then open teaching content appropriate to enhance the professional courses such as Intermediate financial accounting i , cost accounting, administrative institutions of accounting, financial statement analysis, financial management, junior professional accounting qualification examination training.

Practical Course Stressing accounting personnel vocational skills characteristics. Given the training program for the "Accounting + OFFICE / WPS + ERP" primary accounting staff. They should offer accounting and meter class computers and related word processing two types of training courses, including: accounting job training, comprehensive training and accounting positions 0ffice/wps office software training courses, ERP Training Course. Accounting-related training content are: accounting documents fill the trial, settlement of bills, books of registration and reconciliations checkout, Counting, property inventory; payroll, billing and other transactions. Such training not only require students to have a strong practical ability, familiar with accounting procedures, but also required to have more solid accounting treatment capacity. Such as the accounting treatment of income, profit distribution and accounting treatment, tax accounting 
treatment. Finally there is records management training, including certificate binding skills, accounting files and archives keeping skills.

lead by Assistant Accountant exam content, a "vocational education subjects + education" mode. The training program is mainly aimed to obtain primary accounting qualification of this level of vocational students. In with the basic premise of accounting theory and skills, to focus on improving professional skills and have some management skills. So at this level the curriculum is:

Basic Course should be set up: Principles of Accounting, Principles of Accounting computerization economics, principles of management, principles of statistics, financial regulations and accounting professional ethics, economic law, tax law.

Professional courses, in order to strengthen the junior professional accounting qualification examination content, professional courses should be adjusted as follows: Intermediate Financial Accounting, Intermediate Accounting, accounting for business combinations, asset valuation, cost accounting, Administrative and Public Accounting, Finance statement analysis, financial management, junior professional accounting qualification examination training.

Professional practice course, in view of the training program for the "Accounting + ERP + tax" that has some operational capacity accounting workers, we should set up two types of accounting and ERP training courses, computerized accounting training, including financial software maintenance, upgrades and development of skills; in particular, to highlight two major software Kingdee, UF comprehensive training.

Training Course for accounting classes: money management training including reading and writing bills settlement, contract, securities auxiliary account; budget management skills training including the preparation of the overall budget, budget execution skills, interpersonal skills; audit training audit accounting documents including books and financial statements; tax accounting training including tax reporting fill, writing tax documents, tax accounting treatment, check books, property inventory.

In education, the discipline competition is an important part, through the establishment of the school of accounting can contest the progressive realization of the experimental school-related events, routine, in order to stimulate students' interest in participation accounting activities. Actively participate in extracurricular academic competitions, in order to achieve "with competition, in order to promote competition study" purposes, to enhance students' ability to analyze and solve problems.

The accounting discipline competition as higher education in accounting students with some innovative platform that can effectively develop innovation and entrepreneurship of students. The students 'enthusiasm and initiative, and the earth was lit in this process, because more competition in teams appear; the internal team members, namely the division of labor and cooperation we awaken the students' sense of team. Participation in the competitive process, because students will encounter a lot of difficult problems and access to relevant information through various means, which is bound to enable students to accumulate a lot of cutting-edge knowledge and information, and then encourage students to take the initiative to change the way of learning from the past passive learning becomes now active learning by yourself, team co-design competition-related programs, the books on accounting theory with in-depth understanding, which greatly improved the students' ability to innovate.

To carry out accounting skills competitions to promote the continuous improvement of vocational colleges training model, promoting professional development

Since the contents of accounting skills competition and technological progress and social and economic development are closely related, through these events, schools, enterprises can quickly and accurately grasp the latest requirements of the accounting profession skills, vocational colleges can develop talent training according to the accounting information program, adjusting teaching content, teaching mode reform, promote the improvement of teachers' professional teaching level, and ultimately to promote the construction of the entire profession.

Accounting skills competition and cooperation can strengthen school school-enterprise cooperation, improve their employability and competitiveness. Various academic competitions not only strengthened exchanges between students, but also effectively promote exchanges between 
schools, and ultimately achieve the exchange of knowledge. In addition, by the accounting discipline competition but also to promote cooperation between schools and businesses, and participating students can directly access the relevant information through academic competitions enterprises to understand their overall quality. On the basis of school-enterprise cooperation, the school can use its rich culture teaching resources in accordance with their counterparts in accounting personnel needs of enterprises, improve their competitiveness.

\section{References}

[1] Lian Hongda. Under normal background and economic accounting professionals should have the qualities and capabilities. Education. 2015. 09.

[2] Lei Binbin. Xing Dongju. Talents college level institutions of accounting problems and countermeasures, business. 2016. 05.

[3] Wang Cai. Jin Hujiang. School race accounting personnel training objectives under the path fusion research, Market Modernization. 2015.28. 